\title{
Effects of mobile phones electromagnetic radiation on patients with epilepsy: an EEG study
}

\author{
Radwa Azmy ${ }^{1}$, Reham Shamloul2*, Noha Abdalla Farag Elsawy ${ }^{1}$, Saly Elkholy ${ }^{1}$ and Eman Maher ${ }^{1}$
}

\begin{abstract}
Background: Recently, an exceptional increase was witnessed in cell phone users. The brain has greater exposure to the electromagnetic field (EMF) created during mobile phone use than the rest of the body, which may impair its function. In persons with epilepsy, the brain has more tendencies towards electrical instability.

Objectives: The current study aims at investigating the effect of mobile phone radiation (MPR) on the electroencephalogram (EEG) of persons with epilepsy as well as healthy adults.

Subjects and methods: Thirty patients with idiopathic epilepsy and 30 matching controls underwent EEG recording including $15 \mathrm{~min}$ of sham exposure followed by $30 \mathrm{~min}$ of real exposure to MPR and a final postexposure recording for extra 15 min. The number of abnormal EEG events was counted during sham and real exposure for each subject. Correlation analysis was done between the number of epileptic events detected during the real exposure to MPR and the patients' clinical data

Results: In the control group, the EEG under real MPR exposure showed no abnormal discharges. In persons with epilepsy, all those with abnormal EEG during sham exposure MPR (33\%) showed an increase in the number of events with real exposure to MPR. One patient showed a change in the pattern of discharge from interictal changes to an ictal rhythm. Another patient with normal EEG during sham record developed temporal epileptiform discharges during real exposure.

Conclusion: Mobile phone radiation shows recognizable effects on the brain rhythm of persons with epilepsy. These results should be confirmed by future studies to establish a recommendation addressing the use of such devices in epileptic patients.
\end{abstract}

Keywords: Visual EEG analysis, Idiopathic epilepsy, Mobile phone radiation, Electromagnetic field

\section{Introduction}

Shortly after its innovation, the mobile phone became the most important device in daily human life despite the considerable concerns that have been and is still expressed about its possible health risks. The Egypt Ministry of Communications and Information Technology (MCIT) [1] estimated that the number of mobile phone

\footnotetext{
* Correspondence: reham.shamloul@kasralainy.edu.eg

²Department of Neurology, Cairo University, Kasr Alaini Hospital, Al-Manial,

Cairo 11562, Egypt

Full list of author information is available at the end of the article
}

subscriptions was 99.13 million in March 2018, and this number is increasing exponentially.

The close proximity of mobile phones to the user's head makes the brain exposed to a high-specific absorption rate (SAR) of radio-frequency electromagnetic fields (RFEMFs) than other sources of this kind of radiation [2].

The electromagnetic fields of the Global System for Mobile Communications phone (GSM-EMFs) can produce effects on living organisms and brains due to thermal and non-thermal interactions. The detrimental thermal effects on the brain tissue have been extensively studied, and

\section{Springer Open}

(c) The Author(s). 2020 Open Access This article is licensed under a Creative Commons Attribution 4.0 International License, which permits use, sharing, adaptation, distribution and reproduction in any medium or format, as long as you give appropriate credit to the original author(s) and the source, provide a link to the Creative Commons licence, and indicate if changes were made. The images or other third party material in this article are included in the article's Creative Commons licence, unless indicated otherwise in a credit line to the material. If material is not included in the article's Creative Commons licence and your intended use is not permitted by statutory regulation or exceeds the permitted use, you will need to obtain permission directly from the copyright holder. To view a copy of this licence, visit http://creativecommons.org/licenses/by/4.0/. 
exposure limits were established [3], but non-thermal effects are still a matter of debate [4] due to contrasting evidence $[5,6]$.

The effects of EMF have been reported on various experimental models, in vitro [7-10] and in vivo in animals $[11,12]$ and humans $[13,14]$. These effects included alterations in intracellular signaling pathways such as ionic distribution and changes in calcium $(\mathrm{Ca}+2)$ ion permeability $[15,16]$, the increase of cellular excitability, or the activation of cellular response to stress [17]. On the other hand, there are pieces of evidence in the literature, reporting no measurable biological effects on brain functioning following exposure to the GSM-EMFs [18].

In humans, electromagnetic fields like the ones emitted by mobile phones have been suggested to influence the normal brain physiology through changes in cortical excitability modulating the activity of the neural networks towards electrical instability [19, 20].

Since people with epilepsy suffer from abnormal mechanisms of cortical neural synchronization, especially before and during the seizure [21,22] with a tendency toward electrical instability of the neural networks, concerns about the effects of GSM-EMFs are strongly justified and should be investigated. Surprisingly, this possibility appears to have attracted very little attention, at least as regards mobile phone radiation (MPR).

\section{Subjects and methods}

This is a cross-sectional study carried out on adult epileptic patients and healthy matched controls at Cairo University Hospitals, in the period from January to September 2015. In this study, we aimed at investigating and comparing the potential effects of mobile phone radiations (MPR) on resting EEG in healthy adults and epileptic patients using visual EEG analysis.

The patient group included 30 patients, 15 males and 15 females, recruited from the epilepsy clinic with idiopathic epilepsy (either focal or generalized) according to the Commission on Classification and Terminology of the ILAE [23].

The exclusion criteria were (i) patients who experienced seizures in the $24 \mathrm{~h}$ preceding recording session or who recently suffered from a status epilepticus (less than one week), (ii) patients with cognitive impairment, (iii) patients with drug-resistant epilepsy, (iv) patients with psychiatric or medical disorders, and (v) patients receiving drugs interfering with the nervous system other than antiepileptic drugs (AEDs).

The control group included 30 ages and sex-matched healthy control volunteers. The subjects were instructed to refrain from caffeine and to maintain their regular drug administration schedule and cycle of sleeping-waking in the days before the experiment.
All participants were subjected to thorough clinical assessment, including careful general medical assessment and complete neurological examination according to the standard epilepsy sheet of the Neurology Department. Digital EEG recording was carried out while the candidate was lying in a dorsal recumbent position in a semi-illuminated quiet room devoid of any devices omitting radiations as W-LAN or wireless phones, with their eyes gently closed at the clinical neurophysiology unit. In a separate control room, the video EEG was continuously monitored by a technologist utilizing a video-electroencephalograph system with a Neuro Galileo.NT, PMS, USA machine; its serial number is (DAUNL7HQ4NUSFG) with the model (Mizar.B8351037899.Version 3.61).

According to the International 10-20 electrode placement system, a cap was used for each recording with an ear lobe electrode as a reference. The high-frequency filter was $70 \mathrm{~Hz}$, the time constant $0.3 \mathrm{~s}$, and the paper speed 30 $\mathrm{mm} / \mathrm{s}$. The EEG epochs with ocular, muscular, epileptic, and other types of artifacts (including those associated with experimenters' verbal warnings, behavioral, or EEG signs of drowsiness) were offline identified. Two expert electroencephalographers, blind to the effective experimental condition, visually checked and selected the artifact-free EEG epochs to prevent artifacts and interictal epileptic activity from confounding effects of GSM-EMFs.

Each experiment lasted $60 \mathrm{~min}$ and included $15 \mathrm{~min}$ of sham exposure to mobile phone radiation (MPR) during which the mobile phone was in normal mode, but the phone call was addressed off, then the phone call was switched on for the upcoming $30 \mathrm{~min}$ (real exposure to MPR) with no conversation between the sender and the tested candidate. In the last $15 \mathrm{~min}$ of the record, the phone call was addressed off again. Exposure was initiated by calling the patient's phone from a second phone in the adjoining room; the experimenter was to enter the test room to ensure that the subject was awake with eyes closed and turn on the call, which ended by terminating the phone call from the second phone. The patient's phone was set to make no sound/vibration with the call, and the patient was thus ignorant of whether or not it was turned on or off. The test persons did not hold the phone by hand. It was located alongside the head placed $2 \mathrm{~cm}$ away from the participant's left ear to simulate the typical distance of a mobile phone during a call and to avoid the heating effect of the machine. The sender mobile was kept in the observing room during the experimental time.

The subjects' state of vigilance was monitored during the recording session and was alerted every 5 min with a verbal command by the observer to avoid drowsiness. Patients who showed clinical (sluggish response to command) or electrophysiological signs of drowsiness (rhythmic temporal 
theta of drowsiness or vertex waves) during recording were excluded from the study. The experimental conditions were kept the same for all candidates including the timing of the EEG record.

The mobiles used for the present experiment were the commercially available Samsung S3 mini which transmits a typical GSM RF-ON signal with a carrier frequency of $900 \mathrm{MHz}$ and a peak power of $2 \mathrm{~W}$ (equivalent to an average power of $0.25 \mathrm{~W}$ ) and has specific absorption rate (SAR) of $1.03 \mathrm{~W} / \mathrm{kg}$ (head) and $1.28 \mathrm{~W} / \mathrm{kg}$ (body).

Each EEG was analyzed by expert electroencephalographer blind to the effective experimental condition by visual inspection of concurrent split-screen video and EEG. The EEG was visualized for interictal changes suggestive of an epileptic disturbance. Epileptiform activity is defined as abnormal paroxysmal activity consisting, at least in part, of spikes or sharp waves. A spike is defined arbitrarily as a potential having a sharp outline and duration of 20 to $70 \mathrm{msec}$, whereas a sharp wave has a duration between 70 and $200 \mathrm{msec}$. The paroxysmal activity has an abrupt onset and termination, and it can be distinguished clearly from the background activity by its frequency and amplitude [24].

The study was ethically approved by the research committee and reviewed by the Faculty of Medicine Cairo University board (clinical trial number NCT02854384) registration date January 2015. Written informed consent was obtained from all participants involved in this investigation prior to the conduct of any study-related activities.

\section{Statistical analysis}

Data were analyzed using Statistical Program for Social Science (SPSS Inc., Chicago, IL, USA), version 20.0, IBM Corp. 2011. Qualitative data were expressed as frequency and percentage. The number of abnormal EEG events-either focal or generalized of each test person, was counted during sham and real exposure to MPR. For further evaluation, a correlation analysis was performed between the number of epileptic events detected during the real exposure to MPR and the patients' clinical data. For probability, $P$ value $<0.05$ was considered significant.

\section{Results}

Both groups were matched for age and sex, and most patients $(76.7 \%$ in the patient group, $90 \%$ in the control group) involved in the study were $\geq 18$ years old with an equal number of males and females in each group. Further clinical characteristics are summarized in Table 1. All included patients have a normal neurological examination.

The results of the control group before exposure to MPR (sham exposure), during (real exposure), and after exposure, EEG showed normal background activity, with no abnormal focal or paroxysmal discharges.
Table 1 Clinical data of the epileptic patients

\begin{tabular}{|c|c|c|c|}
\hline \multirow[t]{2}{*}{ Clinical data } & \multicolumn{3}{|l|}{ Patients $n=30$} \\
\hline & Item & No. & $\%$ \\
\hline \multirow[t]{4}{*}{ Seizure type } & $\begin{array}{l}\text { Generalized } \\
\text { tonic-clonic } \\
\text { seizures }\end{array}$ & 22 & 73.3 \\
\hline & Absence & 1 & 3.3 \\
\hline & $\begin{array}{l}\text { Focal evolving } \\
\text { to generalized }\end{array}$ & 3 & 10 \\
\hline & $\begin{array}{l}\text { Mixed seizure } \\
\text { types }\end{array}$ & 4 & 13.4 \\
\hline \multirow[t]{2}{*}{ Age of onset } & $<18$ years & 26 & 86.6 \\
\hline & $\geq 18$ years & 4 & 13.4 \\
\hline \multirow[t]{3}{*}{ Duration of disease } & $<5$ years & 2 & 6.7 \\
\hline & $5-15$ years & 21 & 70 \\
\hline & $>15$ years & 7 & 23.3 \\
\hline \multirow[t]{5}{*}{ Last seizure } & $<1$ week & 16 & 53.3 \\
\hline & $1-4$ weeks & 4 & 13.4 \\
\hline & 4-24 weeks & 5 & 16.6 \\
\hline & $\begin{array}{l}24 \text { weeks }-5 \\
\text { years }\end{array}$ & 1 & 3.3 \\
\hline & $\begin{array}{l}\text { Fit free }>5 \\
\text { years }\end{array}$ & 4 & 13.4 \\
\hline \multirow[t]{3}{*}{ Drug profile } & Monotherapy & 10 & 33.3 \\
\hline & Polytherapy & 16 & 53.3 \\
\hline & $\begin{array}{l}\text { Not receiving } \\
\text { antiepileptic drugs }\end{array}$ & 4 & 13.4 \\
\hline
\end{tabular}

${ }^{*} P$ value $<0.05$ is considered statistically significant

The results of the epileptic group are the following: 20 epileptic patients (67\%) had normal EEG record during sham exposure and continued to have normal record during and after real exposure to MPR except one patient who developed focal temporal epileptiform discharges during real exposure to MPR (Fig. 1a, b). This 33-year-old male patient used to experience generalized tonic-clonic convulsions and absence seizures, his last seizure was 2 years ago, and he is not on medication.

Three epileptic patients (10\%) had abnormal focal epileptiform discharges during sham exposure to MPR, and 2 had right anterior temporal discharges while the other had left frontal discharges. The number of abnormal events increased significantly during real exposure and decreased in the after-exposure period. The increase was just in the frequency with the same pre-exposure morphology and distribution (Table 2).

Seven epileptic patients (23\%) had abnormal generalized epileptogenic discharges during the sham exposure to MPR. In five of them (G1, 2, 3, 5, and 6), the number of abnormal events increased significantly during real exposure to MPR and decreased in the after-exposure period (Table 2).

One patient (G4) was an 18-year-old female with absence seizures, not on regular treatment, and her last 


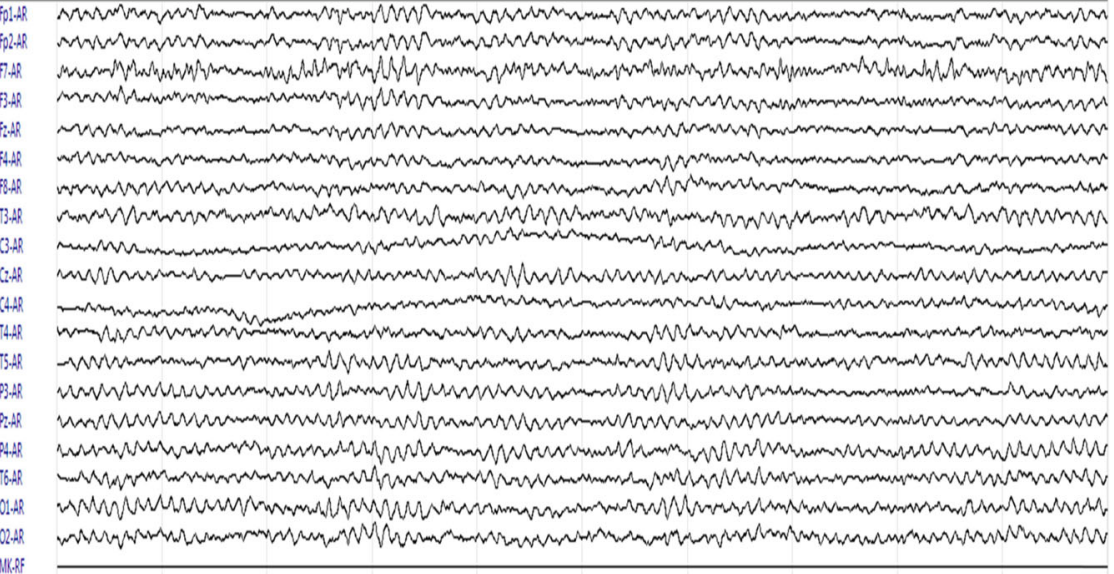

a: Normal EEG record in an epileptic patient during sham exposure to MPR shows normal background activity at $9-10 \mathrm{~Hz}$ alpha waves.

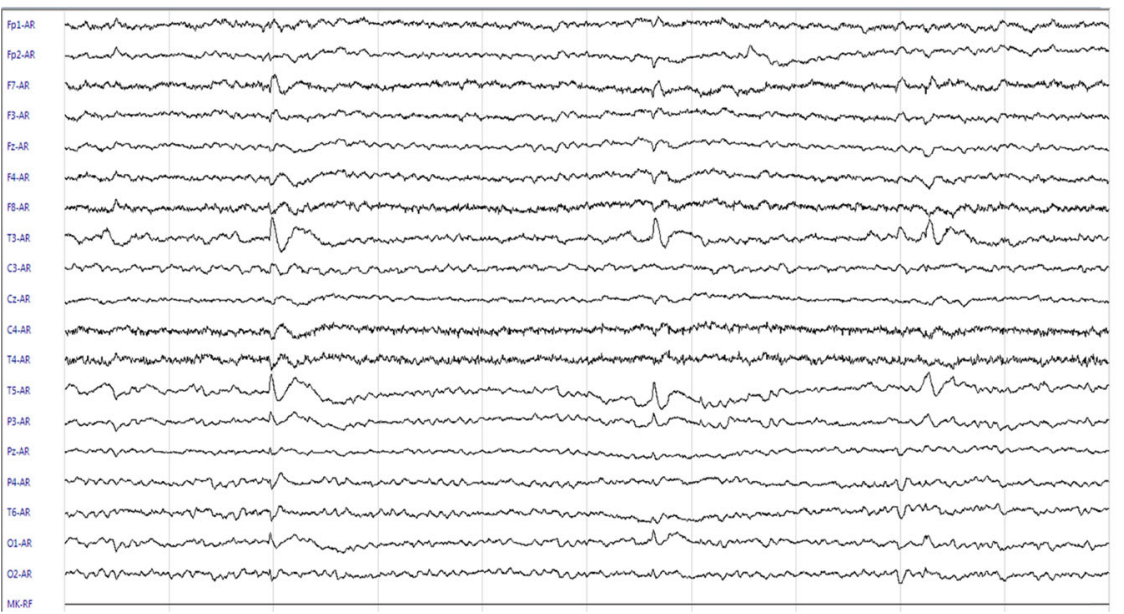

b: Abnormal EEG record during real exposure MPR of the same patient shows left anterior temporal sharpslow wave complex.

Fig. 1 a Normal EEG record in an epileptic patient during sham exposure to mobile phone radiation (MPR) shows normal background activity at 9-10 Hz alpha waves, using a referential montage with gain set on $10 \mathrm{uV}$. b Abnormal EEG record during real exposure to MPR of the same previous patient shows left anterior temporal (T3/T5) sharp-slow wave complexes, using a referential montage with gain set at $15 \mathrm{uV}$. The background activity became slightly slowed at $7-8 \mathrm{~Hz}$

Table 2 Number of epileptic events during sham, real, and after-exposure to MPR

\begin{tabular}{|c|c|c|c|c|c|c|c|c|c|c|}
\hline \multirow[t]{2}{*}{$\begin{array}{l}\text { The number of } \\
\text { events in EEG }\end{array}$} & \multicolumn{3}{|c|}{$\begin{array}{l}\text { Patients with baseline focal } \\
\text { discharges }\end{array}$} & \multicolumn{7}{|c|}{ Patients with baseline generalized discharges } \\
\hline & $\begin{array}{l}\text { Patient } \\
\text { (F1) }\end{array}$ & $\begin{array}{l}\text { Patient } \\
\text { (F2) }\end{array}$ & $\begin{array}{l}\text { Patient } \\
\text { (F3) }\end{array}$ & $\begin{array}{l}\text { Patient } \\
\text { (G1) }\end{array}$ & $\begin{array}{l}\text { Patient } \\
\text { (G2) }\end{array}$ & $\begin{array}{l}\text { Patient } \\
\text { (G3) }\end{array}$ & $\begin{array}{l}\text { Patient } \\
\text { (G4) }\end{array}$ & $\begin{array}{l}\text { Patient } \\
\text { (G5) }\end{array}$ & $\begin{array}{l}\text { Patient } \\
\text { (G6) }\end{array}$ & Patient (G7) \\
\hline $\begin{array}{l}\text { Sham exposure (15 } \\
\text { min) }\end{array}$ & 1 & 1 & 8 & 1 & 2 & 2 & 1 & 1 & 1 & 9 \\
\hline $\begin{array}{l}\text { Real exposure ( } 30 \\
\text { min) }\end{array}$ & 4 & 5 & 30 & 3 & 15 & 15 & 20 & 6 & 10 & $\begin{array}{l}\text { EEG ictal } \\
\text { pattern }\end{array}$ \\
\hline $\begin{array}{l}\text { After exposure ( } 15 \\
\text { min) }\end{array}$ & 0 & 1 & 2 & 3 & 3 & 3 & 10 & 2 & 1 & \\
\hline
\end{tabular}




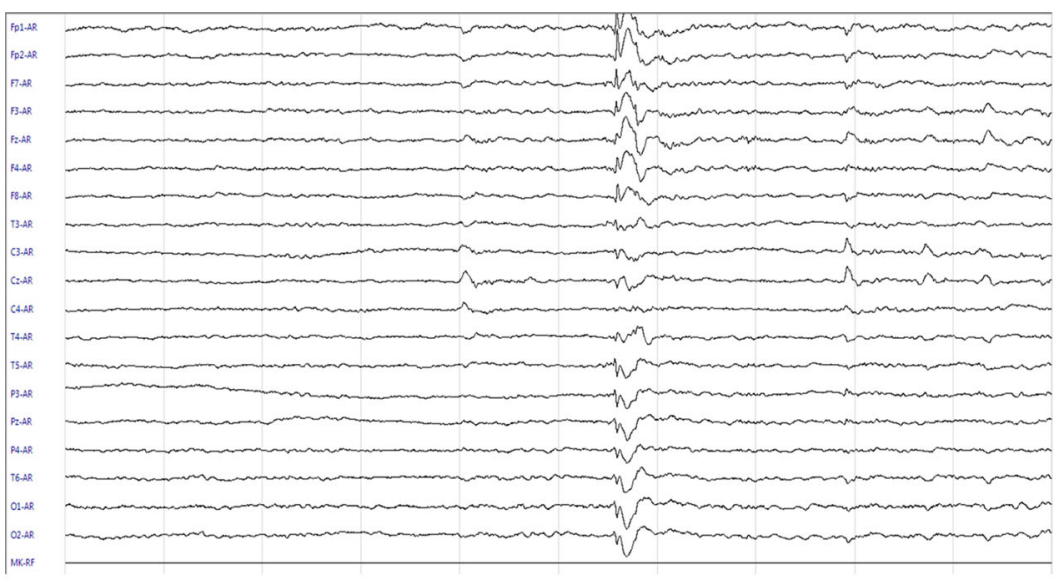

a: Abnormal EEG record during sham exposure MPR of patient G4There is generalized, bilateral, synchronous spike-slow wave complex and sharp wave.

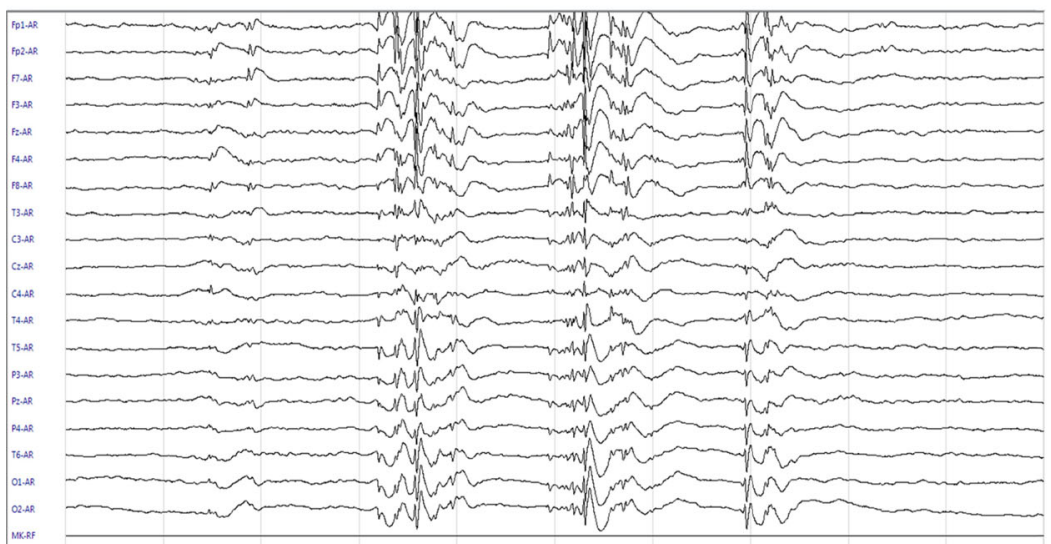

b: Abnormal EEG record during real exposure MPR of the same patient (G4). There is recurrent paroxysm of generalized, bilateral, synchronous polyspike-slow and sharp-slow wave complex.

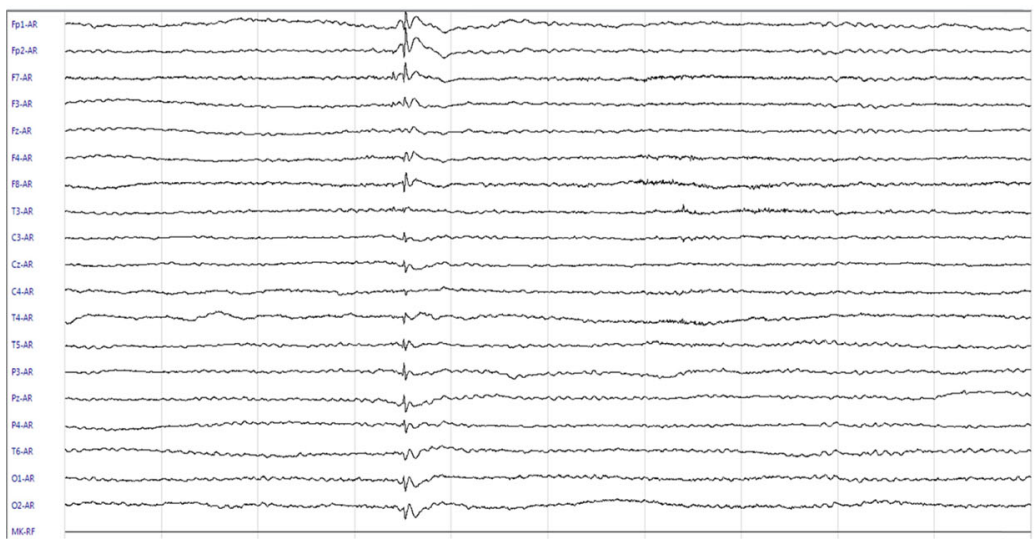

c: Abnormal EEG record after exposure to MPR of the same patient (G4). There is a single paroxysm of

generalized, bilateral and synchronous spike-slow wave complex similar to that recorded during the sham exposure

Fig. 2 (See legend on next page.) 
(See figure on previous page.)

Fig. 2 a Abnormal EEG record during sham exposure to MPR of patient G4, showing generalized, bilateral, synchronous spike-slow wave complex, and sharp wave, using a referential montage with gain set at $15 \mathrm{uV}$. The background activity was $8 \mathrm{~Hz}$. b Abnormal EEG record during real exposure to MPR of the same patient (G4). There is a recurrent paroxysm of generalized, bilateral, synchronous polyspike-slow, and sharpslow wave complexes during which the background activity showed a drop of both frequency and amplitude. A referential montage was used with gain set at $50 \mathrm{uV}$. c Abnormal EEG record at the after-exposure period to MPR of the same patient (G4) showing a brief paroxysm of generalized, bilateral, and synchronous spike-slow wave complexes like that recorded during the sham exposure. A referential montage was used with gain set at $10 \mathrm{uV}$. The background activity resumed its original frequency and amplitude

seizure was 2 days ago. Her EEG continued to be highly abnormal at the after-exposure period (Table 2, Fig. 2a-c)

Patient G7 was an 18-year-old male patient suffering from mixed types of seizures on polytherapy, and his last fit was 2 weeks ago; after $12 \mathrm{~min}$ of real exposure to MPR, his EEG showed a significant change to abundant generalized electrographic ictal discharge. Immediately on observing such an ictal pattern, the phone call was terminated, and the mobile phone was removed away from the patient. The EEG record returned to the basal pattern of reactive posterior alpha rhythm after 5 min (Fig. 3a-c). These EEG changes were not associated with clinical ictal seizure or disturbed awareness.

There is a statistically significant positive correlation between the number of epileptic events detected by visual EEG analysis during the real exposure to MPR and the duration of the disease $(R=0.391, P=0.038)$ while they correlated negatively with the duration elapsed from the last seizure $(R=-0.380, P=0.046)$.

\section{Discussion}

Reports on the effects of EMFs on resting cerebral activity even though ample but unfortunately contradictory [25]. In concordance with current study findings, several studies reported no abnormal effects of RF radiations on humans [26]; however, some of the available data [27, 28] have shown an influence limited to some EEG rhythms, especially on the alpha band (8-13 Hz). Similar findings have also been observed in the spectral content of EEG recorded both prior to sleep onset [29] and during sleep [30].

On the other hand, studies addressing the effects of EMF on the epileptic brain are remarkably scarce with interesting results suggesting a possible influence of these radiations on brain activity.

In the current study, a 30-minute mobile phone call evoked no EEG changes in the control group. No abnormal discharges were developed at any time during or after the phone call. However, in the group, including persons with epilepsy, all of those with abnormal baseline records showed a significant increase in the rate of their interictal EEG discharges on exposure to MPR. In addition, one patient with normal basal record developed left focal temporal epileptiform discharges taking into consideration that the mobile phone was put on the left side. Such discharges decreased after the end of the call but did not reach the basal pattern in most patients till the end of the record.

In a study done by López-Martín and colleagues [31], they found that $900 \mathrm{MHz}$ GSM radiation triggered a marked increase in neuronal excitability in seizure-prone rats, as manifested by behavioral indicators, EEG indicators, and neuronal c-Fos expression. Cinarand colleagues [32] also investigated the effects of exposure to different frequencies of EMWs in various durations in a mouse epilepsy model induced by pentylenetetrazole (PTZ), and they found that acute exposure to EMW may facilitate epileptic seizures by shortening initial seizure latency, which may be independent of EMW exposure time. Similarly, Persinger and Belanger-Chellew [33] observed an increase in the incidence of seizures in rats when mean-field intensity was raised.

Vecchio and colleagues found that epileptic patients showed a statistically significant higher inter-hemispheric coherence of temporal and frontal alpha rhythms in the GSM than "sham" condition compared with the control subjects. These results suggest that GSM-EMFs of a mobile phone may affect inter-hemispheric synchronization of the dominant (alpha) EEG rhythms in epileptic patients as a reflection of a higher cortical synchronization in epilepsy-related condition [20].

On the contrary, other studies highly question hyperexcitability theory and propose an opposite assumption that MPR increases the inhibitory GABA neurotransmitter, thus decreasing EEG discharges and clinical seizures. Curcio and colleagues [25] reported a decrease in spike firing rates in 12 patients with focal epilepsy. Nagarjunakonda and colleagues [34] stated that drug-resistant epilepsy improved with a significant decrease in fits in mobile users. Taking into consideration that the latter study monitored clinical fits, not EEG, also they were assessing chronic, not acute MPR exposure. For the former study, automated spike count was used and not visual analysis.

Another debatable point that is still under research is the effect of MPR on background rhythm. Researchers have reported contradictory changes concerning the effect of MPR exposure on alpha activity using quantitative electroencephalography. El Sawy and colleagues [35] found that there was a decrease in alpha band power in healthy 


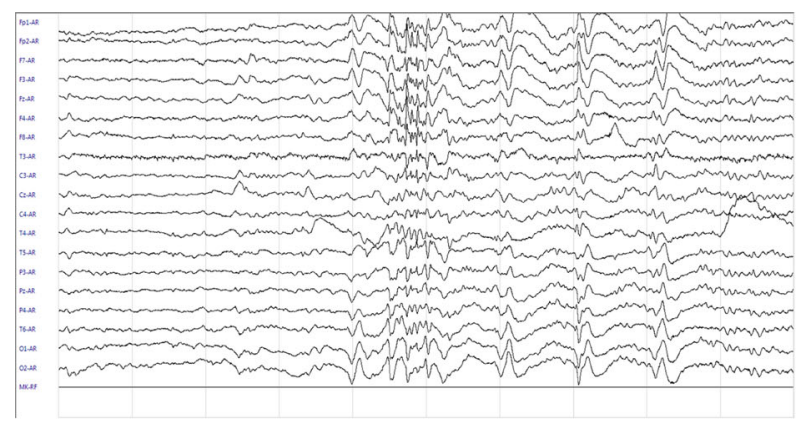

a: Abnormal EEG record during sham exposure MPR of patient (G7 There is paroxysm of generalized, bilateral, synchronous spike-slow, sharp-slow wave complexes

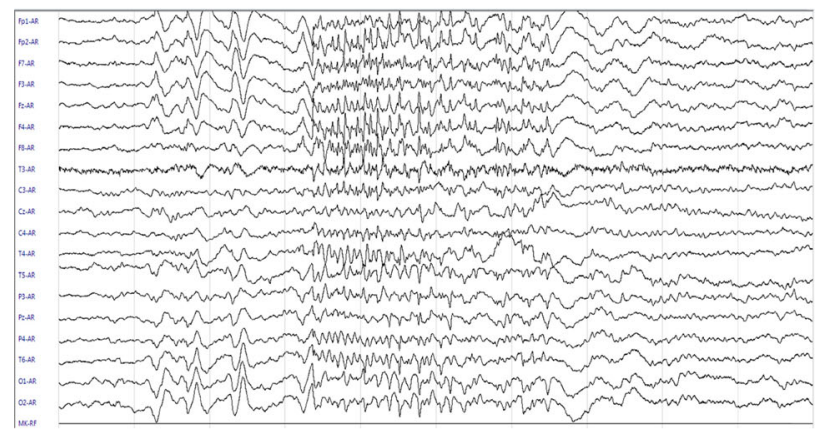

b1: Abnormal EEG record during real exposure MPR for the same patient (G7)

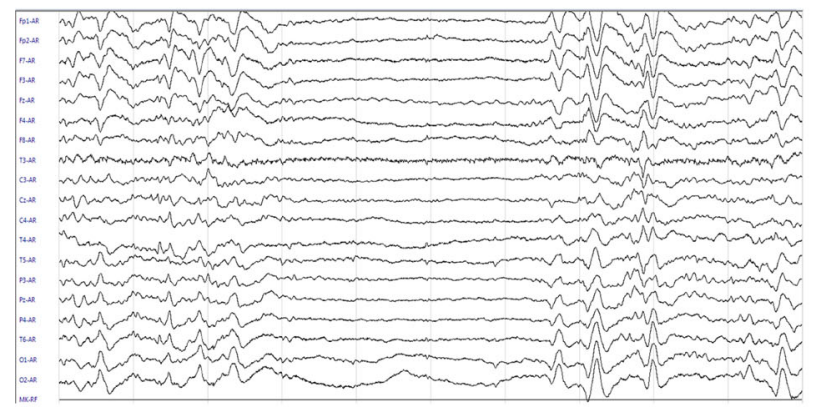

b2: Abnormal EEG record during real exposure MPR for the same patient (G7)

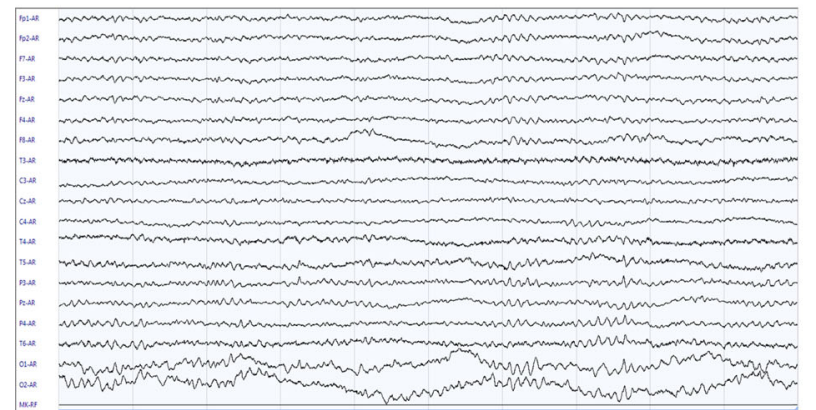

c: EEG record 5 minutes after termination of the phone call of the same patient (G7).. It shows normalization of the background activity (8-9 $\mathrm{Hz}$ alpha waves).

Fig. 3 (See legend on next page.) 
(See figure on previous page.)

Fig. 3 a Abnormal EEG record during sham exposure to mobile phone radiation (MPR) of patient G7. There is paroxysm of generalized, bilateral, synchronous spike-slow, and sharp-slow wave complexes, the background activity. A referential montage was used and gain set at 10 uV. b1, b2 Abnormal EEG record during real exposure to MPR for the same patient (G7). A referential montage gain was set on $20 \mu \mathrm{v}$. There are spontaneous bursts of recruiting building up pattern of generalized bisynchronous, symmetrical polyspikes that are discharging "fast"; at a rate of 6 and $10 \mathrm{~Hz}$ with extremely short periods of near-normal background activity that lasted for more than $30 \mathrm{~s}$ (B1), followed by high-voltage, irregular 2- to 5-Hz slow waves with intermixed spikes (B2). c EEG record 5 min after termination of the phone call of the same patient (G7). It shows normalization of the background activity (8-9 Hz alpha waves). Gain set at $10 \mathrm{uV}$

resting adults and in epileptic patients on applying MPR. Moreover, the alpha band power continued to change in a non-linear manner after exposure in healthy subjects and even more profoundly in epileptic patients. Vecchio and colleagues [20] also reported a reduction in alpha power after exposure, while Relova and colleagues [36] reported an increase in alpha band power upon exposure in epileptic patients. From the previous studies' results, changes in the alpha rhythm are expected to occur concurrently with the epileptiform discharge activation.

To our knowledge, the present results show evidence of peculiar effects of GSM-EMFs on resting EEG in epilepsy patients and extend to humans the previous evidence of GSM-EMFs induced cortical activation in a seizure-proneness rat model [37] and also confirms an increase in the interictal epileptiform activity.

Also, from the present results, we can suggest that patients who are known to be epileptic for longer periods or have experienced seizures lately are at a higher risk from the effects of acute MPR as detected from the correlation analysis.

A note of caution is needed regarding the interpretation of the current study data. Some degree of variability of alertness would be expected in comparison with studies with shorter protocols, as the real exposure to MPR started after $15 \mathrm{~min}$ of staying in a quite semiilluminated room. Although the authors tried to eliminate the effect of drowsiness, its provocative effect should be taken into consideration. Second, the same day protocol of real and sham exposure allowed unifying the exposure settings.

\section{Conclusion}

By having a top view on these results, one can see that though changes were detected in some patients, yet no evident effect was detected in controls as well as most of the patients with normal baseline records. Thus, a conclusive interpretation of the present results is still premature, and it can just be speculated that EMFs like the ones emitted by mobile phones may influence the epileptic brain, probably through changes in cortical excitability. Also, further studies on humans should be carried out to show possible dose-related effects, particularly concerning chronic or repeated exposures.

\section{Acknowledgements}

Not applicable

\section{Authors' contributions}

All authors contributed to the research idea. NAFE and RS contributed to the data collection. SE, RA, and EM analyzed the data and along with NAFE and RS who interpreted the data. Further SE, RA, EM, and RS completed the first draft of the article. All authors were involved in revising it critically for important intellectual content, and all authors approved the final version to be published.

\section{Funding}

There is no source of funding for this research.

\section{Availability of data and materials}

All datasets generated and analyzed during the current study are not publicly available, but are available by a reasonable request from the corresponding author.

\section{Ethics approval and consent to participate}

All procedures performed in the study were in accordance with the ethical standards of the institutional research committee and with the 1964 Helsinki declaration and its later amendments. The study was ethically approved by the research committee and reviewed by the Faculty of Medicine Cairo University board (clinical trial number NCT02854384) registration date January 2015.

\section{Consent for publication}

Written informed consent was obtained from all participants involved in this investigation prior to the conduct of any study-related activities.

\section{Competing interests}

The authors declare that they have no competing interests (financial and non-financial).

\section{Author details}

${ }^{1}$ Clinical Neurophysiology Unit, Cairo University, Kasr Alaini Hospital, Cairo 11562, Egypt. ${ }^{2}$ Department of Neurology, Cairo University, Kasr Alaini Hospital, Al-Manial, Cairo 11562, Egypt.

Received: 20 March 2019 Accepted: 26 February 2020 Published online: 16 March 2020

\section{References}

1. The Ministry of Communications and Information Technology Egypt Sector Indicators [Internet]. Available from: http://www.mcit.gov.eg/Upcont/ Documents/Publications_362018000_ICT Indicators inbrief_April_2018_EN. pdf.

2. Kuster N. N., Balzano Q and LJC. Mobile communications safety. first. London: Chapman and Hall; 1997. 1-269 p.

3. Hyland G. Physics and biology of mobile telephony. Lancet. 2000.

4. International Commission on Non-lonizing Radiation Protection. Guidelines for limiting exposure to time-varying electric, magnetic, and electromagnetic fields (up to $300 \mathrm{GHz}$ ). Health Phys. 1998;74:494-522.

5. Zhu Y, Gao F, Yang X, Shen H, Liu W, Chen H, et al. The effect of microwave emission from mobile phones on neuron survival in rat central nervous system. Prog Electromagn Res. 2008;82:287-98.

6. Repacholi MH. Low-level exposure to radiofrequency electromagnetic fields: health effects and research needs. Bioelectromagnetics. 1998;19:1-19. 
7. Leszczynski D. Mobile phones, precautionary principle, and future research [9]. Lancet. 2001;358(9294):1733.

8. Leszczynski D, Joenväärä S, Reivinen J, Kuokka R. Non-thermal activation of the hsp27/p38MAPK stress pathway by mobile phone radiation in human endothelial cells: molecular mechanism for cancer- and blood-brain barrierrelated effects. Differentiation. 2002;70(2-3):120-9.

9. Nylund R, Leszczynski D. Proteomics analysis of human endothelial cell line EA.hy926 after exposure to GSM 900 radiation. Proteomics. 2004;4(5):135965.

10. Sarimov R, Malmgren LOG, Markovà E, Persson BRR, Belyaev IY. Nonthermal GSM microwaves affect chromatin conformation in human lymphocytes similar to heat shock. IEEE Trans Plasma Sci. 2004;32:1600-8.

11. Buttiglione M, Roca L, Montemurno E, Vitiello F, Capozzi V, Cibelli G. Radiofrequency radiation $(900 \mathrm{MHz})$ induces Egr-1 gene expression and affects cell-cycle control in human neuroblastoma cells. J Cell Physiol. 2007; 213(3):759-67.

12. Shallom JM, Di Carlo AL, Ko D, Miguel Penafiel L, Nakai A, Litovitz TA. Microwave exposure induces $\mathrm{Hsp} 70$ and confers protection against hypoxia in chick embryos. J Cell Biochem. 2002;86(3):490-6.

13. Ilhan A, Gurel A, Armutcu F, Kamisli S, Iraz M, Akyol O, et al. Ginkgo biloba prevents mobile phone-induced oxidative stress in rat brain. Clin Chim Acta. 2004;340(1-2):153-62.

14. Moustafa YM, Moustafa RM, Belacy A, Abou-El-Ela SH, Ali FM. Effects of acute exposure to the radiofrequency fields of cellular phones on plasma lipid peroxide and antioxidase activities in human erythrocytes. J Pharm Biomed Anal. 2001;26(4):605-8.

15. Ferreri F, Curcio G, Pasqualetti P, De Gennaro L, Fini R, Rossini PM. Mobile phone emissions and human brain excitability. Ann Neurol. 2006;60(2):18896.

16. Hossmann K-A, Hermann DM. Effects of electromagnetic radiation of mobile phones on the central nervous system. Bioelectromagnetics. 2003;24:49-62.

17. Tattersall JE, Scott IR, Wood SJ, Nettell JJ, Bevir MK, Wang Z, et al. Effects of low intensity radiofrequency electromagnetic fields on electrical activity in rat hippocampal slices. Brain Res. 2001;61:435-514.

18. Krause CM, Haarala C, Sillanmäki L, Koivisto M, Alanko K, Revonsuo A, et al. Effects of electromagnetic field emitted by cellular phones on the EEG during an auditory memory task: a double blind replication study. Bioelectromagnetics. 2004;25(1):33-40.

19. Beason RC, Semm P. Responses of neurons to an amplitude modulated microwave stimulus. Neurosci Lett. 2002;333:175-8.

20. Vecchio F, Tombini M, Buffo P, Assenza G, Pellegrino G, Benvenga A, et al. Mobile phone emission increases inter-hemispheric functional coupling of electroencephalographic alpha rhythms in epileptic patients. Int J Psychophysiol. 2012;82(2):164-71.

21. Schindler K, Leung $H$, Elger CE, Lehnertz K. Assessing seizure dynamics by analysing the correlation structure of multichannel intracranial EEG. Brain. 2007;130:65-77.

22. Hefter H, Witte OW, Reiners K, Niedermeyer E, Freund HJ. High frequency bursting during rapid finger movements in an unusual case of epilepsia partialis continua. Electromyogr Clin Neurophysiol. 1994;34(2):95-103.

23. Proposal for Revised Classification of Epilepsies and Epileptic Syndromes: Commission on Classification and Terminology of the International League Against Epilepsy. Epilepsia. 1989;30(4):389-99.

24. Aminoff MJ. Electrodiagnosis in clinical neurology. Electrodiagnosis in Clinical Neurology. 2005.

25. Curcio G, Ferrara M, Moroni F, D'Inzeo G, Bertini M, De Gennaro L. Is the brain influenced by a phone call? An EEG study of resting wakefulness. Neurosci Res. 2005;53:265-70.

26. Hietanen M, Kovala T, Hämäläinen AM. Human brain activity during exposure to radiofrequency fields emitted by cellular phones. Scand J Work Environ Heal. 2000;26:87-92.

27. Reiser H, Dimpfel W, Schober F. The influence of electromagnetic fields on human brain activity. Eur J Med Res. 1995;1:27-32.

28. Croft RJ, Chandler JS, Burgess AP, Barry RJ, Williams JD, Clarke AR. Acute mobile phone operation affects neural function in humans. Clin Neurophysiol. 2002;113:1623-32.

29. Huber R, Treyer V, Borbély AA, Schuderer J, Gottselig JM, Landolt HP, et al. Electromagnetic fields, such as those from mobile phones, alter regional cerebral blood flow and sleep and waking EEG. J Sleep Res. 2002;11:289-95.
30. Borbély AA, Huber R, Graf T, Fuchs B, Gallmann E, Achermann P. Pulsed high-frequency electromagnetic field affects human sleep and sleep electroencephalogram. Neurosci Lett. 1999;275:207-10.

31. López-Martín E, Relova-Quinteiro JL, Gallego-Gómez R, Peleteiro-Fernández $\mathrm{M}$, Jorge-Barreiro FJ, Ares-Pena FJ. GSM radiation triggers seizures and increases cerebral c-Fos positivity in rats pretreated with subconvulsive doses of picrotoxin. Neurosci Lett. 2006;398:139-44.

32. Cinar N, Sahin S, Erdinc O. What is the impact of electromagnetic waves on epileptic seizures? Med Sci Monit Basic Res. 2013;19:141-5.

33. Persinger MA, Belanger-Chellew G. Facilitation of seizures in limbic epileptic rats by complex 1 microTesla magnetic fields. Percept Mot Skills. 1999;89: 486-92.

34. Nagarjunakonda S, Amalakanti S, Uppala V, Gajula RK, Tata RS, Bolla HB, et al. Mobile phones and seizures: drug-resistant epilepsy is less common in mobile-phone-using patients. Postgrad Med J. 2017;93(1095):25-8.

35. Elsawy N, Elkholy S, Azmy R, Maher EA, Shamloul R. Electrophysiological assessment of the impact of mobile phone radiation on cognition in persons with epilepsy. J Clin Neurophysiol. 2019.

36. Relova JL, Pérlega S, Vilar JA, López-Marlin E, Peleteiro M, Ares-Pena F. Effects of cell-phone radiation on the electroencephalographic spectra of epileptic patients. IEEE Antennas Propag Mag. 2010.

37. López-Martín ME, Brøgains J, Relova-Quinteiro JL, Cadarso-Suárez C, JorgeBarreiro FJ, Ares-Pena FJ. The action of pulse-modulated GSM radiation increases regional changes in brain activity and c-Fos expression in cortical and subcortical areas in a rat model of picrotoxin-induced seizure proneness. J Neurosci Res. 2009;87(6):1484-99.

\section{Publisher's Note}

Springer Nature remains neutral with regard to jurisdictional claims in published maps and institutional affiliations.

\section{Submit your manuscript to a SpringerOpen ${ }^{\circ}$ journal and benefit from:}

- Convenient online submission

- Rigorous peer review

- Open access: articles freely available online

High visibility within the field

- Retaining the copyright to your article

Submit your next manuscript at $>$ springeropen.com 